\title{
Blast Furnace Slag as a Raw Material to Manufacture Gamma-Ray Transparent Shield Glass
}

\author{
A. M. Abdel_Ghany ${ }^{1,}{ }^{*}$, A. M. Zoulfakar ${ }^{2}$, T. Z. Abou-Elnasr ${ }^{2}$, M. Y. Hassaan ${ }^{2}$, A. G. Mostafa ${ }^{2}$ \\ ${ }^{1}$ Basic Science Dept., Faculty of Engineering Science, Sinai Univ., El-Arish City, Egypt \\ ${ }^{2}$ ME Lab., Phys. Dept., Faculty of Science, Al-Azhar Univ., Nasr City, Cairo, Egypt
}

Email address:

ah_gh83@yahoo.com (A. M. Abdel_Ghany)

\section{To cite this article:}

A. M. Abdel_Ghany, A. M. Zoulfakar, T. Z. Abou-Elnasr, M. Y. Hassaan, A. G. Mostafa. Blast Furnace Slag as a Raw Material to Manufacture Gamma-Ray Transparent Shield Glass. " merican Journal of Physics and "pplications. Vol. 3, No. 6, 2015, pp. 208-214. doi: 10.11648/j.ajpa.20150306.14

\begin{abstract}
Some phosphate glass samples containing $30 \mathrm{~mol} \%$ blast furnace slag (as iron industrial waste) and $20 \mathrm{~mol} \%$ heavy metal oxides (cadmium and lanthanium) have been prepared by the melt quenching method. It was found that as $\mathrm{La}_{2} \mathrm{O}_{3}$ was gradually increased at the expense of $\mathrm{CdO}$, gamma-ray attenuation coefficient increased while the half value layer decreased. Density and molar volume as well as the number of oxygen ion density increased gradually also. From the obtained data, it appeared that, these glasses act as suitable gamma-ray shield especially at high energies. The samples exhibit also semiconductor properties and have mixed conduction mechanisms of both $C B H$ and $S P H$ models. The electrical conductivity showed a decrease with the gradual increase of $\mathrm{La}_{2} \mathrm{O}_{3}$ content.
\end{abstract}

Keywords: Oxide Glass, Mass Attenuation Coefficient, Density, Electrical Conductivity, Dielectric Constant

\section{Introduction}

"Slag" is a general word used to define the residue drawn off in the process of refining a metal from its ore. Iron slag is a by-product formed during the process of pig iron manufacturing in blast furnace. That is blast furnace slag (BFS) is the residue of pig iron production and based on the world steel annual manufacturing, approximately 150 million metric tons of slag are produced every year [1]. The amount of slag produced in Egypt is about 300.000 ton per year. Little amount can be used as a raw material for cement industry, production of bricks and in road pavement. The major amount is directly discharged in landfills which consequently cause environmental problems and cause damage to the ecological environment, since the level of utilization technology is very poor [2-4].

The chemical composition of BFS is very much like that of calcium-silicate glass and it can be used to manufacture glass and ceramics, with high quality, low price, corrosion proof ...etc. These products can be applied to manufacture conscious materials [4]. Therefore it was previously recommended that a small unit for glass or ceramic manufacturing must be constructed in any iron industrial factory [5].
From another point of view, phosphate glasses have been investigated for a variety of applications. Rare-earth containing meta-phosphate glasses possess high stimulated emission cross-sections and low thermo-optical coefficients. Also, they represent the primary host materials for high-power laser applications [6]. In addition to their low transition temperature (about $365^{\circ} \mathrm{C}$ ), high thermal expansion coefficients, high electrical conductivity, high ultraviolet $U V$ transmission and high solubility for rare earth ions compared with silica $[7,12]$. Despite $\mathrm{P}_{2} \mathrm{O}_{5}$ being one of the four classic Zachariasen glass forming oxides (along with $\mathrm{SiO}_{2}, \mathrm{GeO}_{2}$ and $\mathrm{B}_{2} \mathrm{O}_{3}$ ) but its hygroscopic nature makes their development very limited. It was found that the addition of at least $30 \mathrm{~mol} \%$ metal oxides, significantly improve the durability of these glass and hence their possible applications actively pursued. These properties makes them useful candidates as shielding glass for fast ion conducting materials [6], laser host matrices after doping with rare-earth elements [13,14], glass to-metal seals [15] and for the immobilization and disposal of nuclear waste materials [16-18]. Good reviews about high lead phosphate glasses as radiation shielding materials and development have been published recently by several authors. These glasses have radiation resistance at doses up to $107 \mathrm{R}$ and has an optical 
transmission edge at $360 \mathrm{~nm}$. The absorption coefficient of gamma radiation of phosphate glasses is larger than that of dense silicate flints. Recently, this result appeared very interesting for making phosphate glass as good radiation shielding materials [19-21].

However, in this article, a trial will be done to prepare some phosphate glasses consisting considerable amount of BFS (not less than 30\%) in addition to additives of some heavy metal oxides, aiming to manufacture low cost, good transparent and effective shielding for harmful rays.

\section{Experimental Work}

Glasses of the nominal composition $\left(50 \% \mathrm{P}_{2} \mathrm{O}_{5}-30 \%\right.$ BFS - (20-x) $\% \mathrm{CdO}-\mathrm{x} \% \mathrm{La}_{2} \mathrm{O}_{3},(\mathrm{x}=0,2,4,6$ and $8 \mathrm{~mol} \%)$, were prepared by the conventional melt quenching method. The glass samples were prepared from analytically pure grade lanthanum oxide, cadmium oxide, ammonium di-hydrogen phosphate and slag (the major composition is about $37 \% \mathrm{SiO}_{2}, 12 \% \mathrm{Al}_{2} \mathrm{O}_{3}, 50 \% \mathrm{CaO}$ and $1 \%$ traces of some transition metal oxides). Batches -to produce $20 \mathrm{~g}$ - of each glass sample were placed in porcelain crucibles and heated from room temperature until $1200^{\circ} \mathrm{C}$ gradually to expel water and ammonia. Then melts were left at $1200^{\circ} \mathrm{C}$ for $2 \mathrm{~h}$. During melting the crucibles were stirred several times in order to obtain homogenous glass and the melts were then quenched at room temperature. Just, after sitting the solid glasses were directly transferred to the annealing furnace at $250^{\circ} \mathrm{C}$ and the furnace was turned off and was left to cool to room temperature over-night.

All samples were examined visually, where they were found free from visible in-homogeneities, such as inclusions, cracks or air bubbles, as well as they were found optically transparent.

The values of the total mass attenuation coefficients of the studied glasses were calculated applying Win X-COM program, based on the mixture rule,

$$
\left(\frac{\mu}{\rho}\right)_{m(t o t a l)}=\sum_{i=0}^{n} w_{i}\left(\frac{\mu}{\rho}\right)_{m(i)}
$$

where $(\mu / \rho)_{m}$ is the total mass attenuation coefficient for a glass sample and $\mathrm{w}_{\mathrm{i}}$ is the fractional weight of the oxides in each component.

The half value layers $(H V L)$ of the studied glass were also calculated according to the equation:

$$
\mathrm{HVL}=0.693 / \mu
$$

The density values were measured to detect the change in the internal network structure as the composition was gradually changed. The measurements were carried out by applying Archimedes principle using toluene as an emersion liquid of stable density $\left(\mathrm{d}=0.8655 \mathrm{~g} / \mathrm{cm}^{3}\right)$.

For electrical conductivity measurements, the solid glasses were polished to obtained disk shape samples with 7 $\mathrm{mm}$ diameter and $1 \mathrm{~mm}$ thickness, and the measurements were performed using LRC Bridge (model SR 270) at three fixed frequencies $1,10,100 \mathrm{kHz}$. The samples were polished, cleaned and sandwiched between two electrodes of silver paste to obtain good electrical contact. The ohmic contact was checked by measuring the I-V behavior from zero until $100 \mathrm{dc}$ Volt. The measurements were performed in the temperature range from room temperature up to $575^{\circ} \mathrm{K}$.

\section{Results and Discussion}

Nowadays, owing to the universal uses of many types of radio-active sources in various life fields (medicine, industry, agriculture ... etc), daily life becomes dangerous especially for users, since they have to be in contact to different harmful rays. However, the search for suitable shielding materials becomes now of interest. On this sense, the prepared glasses were checked whether they can be used as transparent shield or not.

The $\gamma$-ray attenuation coefficients $(\mu / \rho)$ have been calculated using Win X-COM program at energies equal to $356,662,1173$ and $1332 \mathrm{KeV}$ as low energy $\gamma$-ray and at energies equal to $20,40,60$ and $80 \mathrm{MeV}$ as high energy $\gamma$-ray. Fig. (1) represents the change in the $\gamma$-ray mass attenuation coefficient with the gradual increase of lanthanum oxide at the expense of cadmium oxide. A gradual increase of the mass attenuation coefficient of $\gamma$-ray (low energy) can be easily observed. The onset drown inside this figure shows obviously the observed increase. Similarly, Fig. (2) shows the change in the mass attenuation coefficient of the studied glasses at high $\gamma$-ray energies. It appeared that as lanthanum oxide was gradually increased, the mass attenuation coefficient increased also.

The $H V L$ of the studied glasses was also calculated for the same $\gamma$-ray energy values. The obtained values as a function of lanthanum oxide are represented graphically in Fig.s (3 \& 4) for low and high $\gamma$-ray energys respectively. It can be seen obviously that the HVL decreased gradually with the gradual increase of lanthanum oxide content.

The observed increase in the $\gamma$-ray mass attenuation coefficient as well as the corresponding decrease in the half value layer of the studied glasses can be attributed to the gradual replacement of cadmium oxide by lanthanum oxide. This can be understood logically by knowing that the $\gamma$-ray mass attenuation coefficient and the half value layer of lanthanum and cadmium oxides for $662,1332 \mathrm{KeV}$ energies are $(0.079,0.05018)_{\mathrm{La} 2 \mathrm{O} 3} \mathrm{~cm}^{2} / \mathrm{g},(0.054,0.05)_{\mathrm{CdO}} \mathrm{cm}^{2} / \mathrm{g}$ and $(1.35,2.12)_{\mathrm{La}_{203},(1.58,1.69)_{\mathrm{CdO}}} \mathrm{cm}$ respectively.

In addition to this, it can be supposed that the gradual increase of lanthanum cations in the network of these glasses may act to increase gradually their density. However, the density of these samples was measured applying Archemides principle using toluene as an immersion liquid of stable density. Fig. (5) shows the change in the density values measured experimentally, and in the same figure, the change in the empirical density was also depicted for comparison.

As was expected, Fig. (5) shows that both the experimental and empirical densities increased gradually as $\mathrm{La}_{2} \mathrm{O}_{3}$ was 
gradually increased. The calculated empirical density was found to be higher than that of the experimental one. This can be taken as evidence for the amorphous nature of the prepared glass samples.

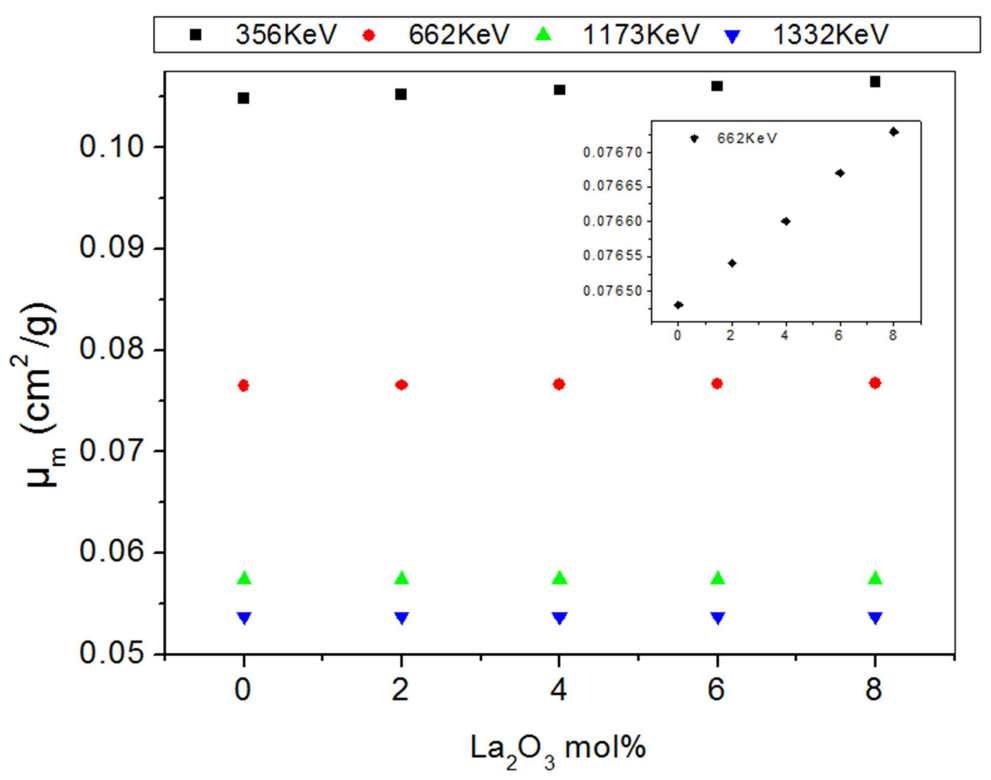

Fig. (1). The mass attenuation coefficient versus $\mathrm{La}_{2} \mathrm{O}_{3}$ content for different low $\gamma$-ray energies.

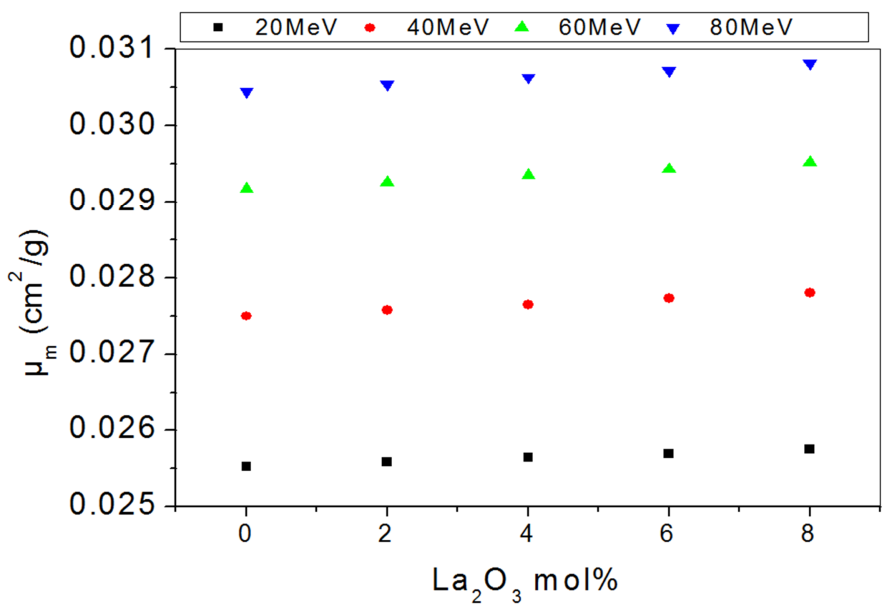

Fig. (2). The mass attenuation coefficient as a function of $\mathrm{La}_{2} \mathrm{O}_{3}$ content for different high $\gamma$-ray energies.

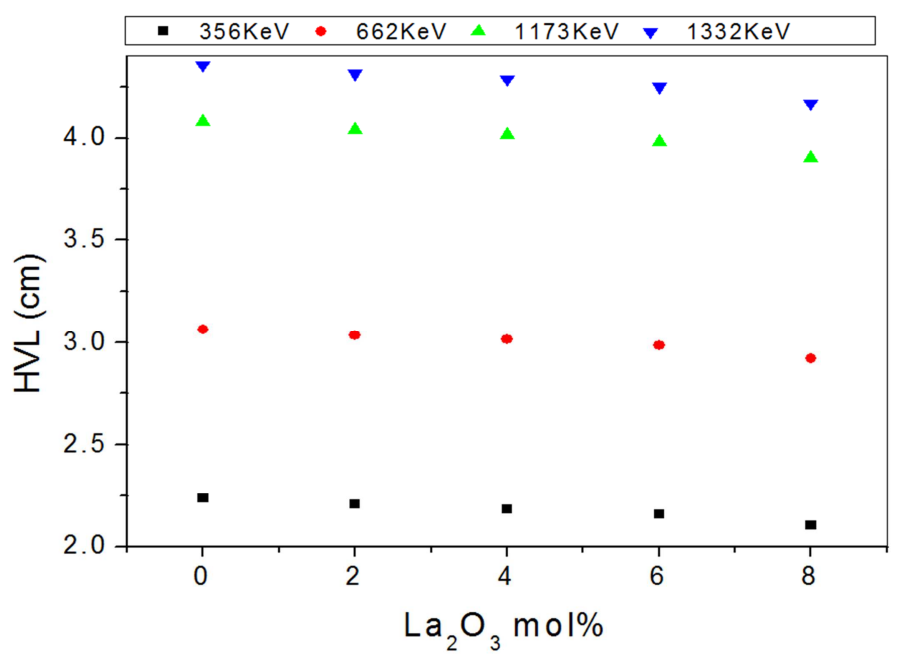

Fig. (3). The HVL of the investigated glasses versus $\mathrm{La}_{2} \mathrm{O}_{3}$ content for different low $\gamma$-ray energies. 


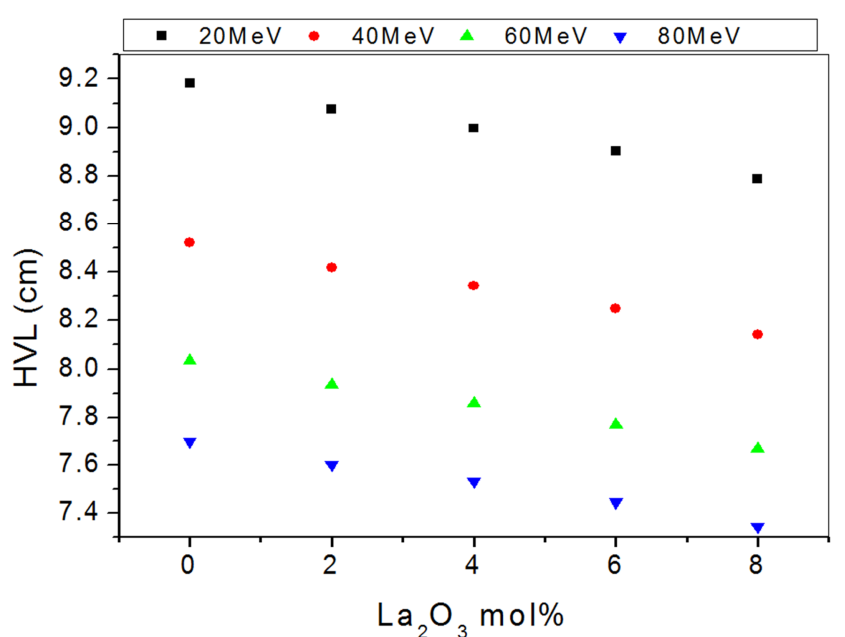

Fig. (4). The HVL of the investigated glasses versus $\mathrm{La}_{2} \mathrm{O}_{3}$ content for different high $\gamma$-ray energies.

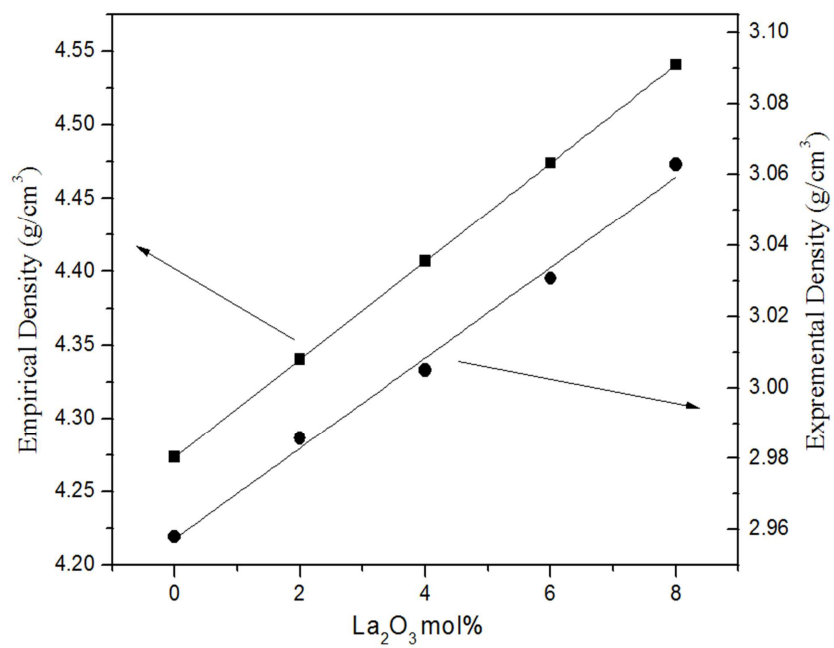

Fig. (5). The variation of both the experimental and empirical density versus $\mathrm{La}_{2} \mathrm{O}_{3}$ content.

The gradual increase in the density values can be attributed to:

[1] The replacement of one mole of $\mathrm{CdO}$ (molecular weight $=128.41 \mathrm{~g} / \mathrm{mol}$ ) by one mole of $\mathrm{La}_{2} \mathrm{O}_{3}$ (molecular weight $=$ $325.809 \mathrm{~g} / \mathrm{mol}$ ).

[2] The replacement of one Cd cation (ionic radii $\mathrm{R}_{\mathrm{i}}=109$ Pico meter $(\mathrm{Pm})$ ) by two La cations (ionic radii of each, $\mathrm{R}_{\mathrm{i}}=$ 117.2 Pm)

On the other hand, it is well known fact that the molar volume $V_{m}$ can gave well defined explanation about the spatial structure of the glass networks. Therefore, Fig. (6) shows the gradual change in the molar volume of the studied glasses as lanthanum oxide was gradually increased in the glass network at the expense of cadmium oxide. The empirical molar volume was also represented in the same figure for comparison, where a gradual linear increase was clearly observed in both values of the empirical and experimental $V_{m}$.

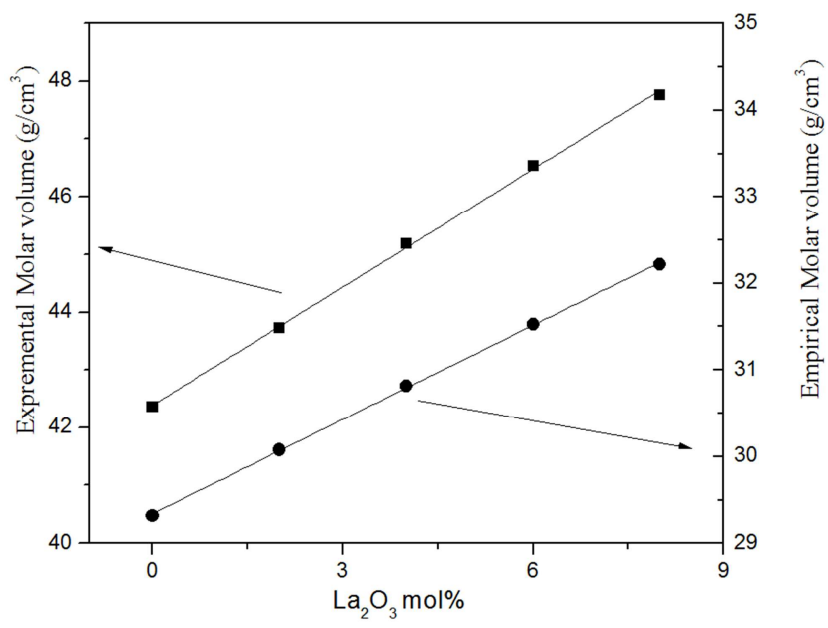

Fig. (6). The variation of both the experimental and the empirical $V_{m}$ versus $\mathrm{La}_{2} \mathrm{O}_{3}$ content.

It is obvious from this figure that the experimental $V_{m}$ is higher than that of the empirical one, which can be taken also as evidence that the prepared samples are of homogenous glassy phase.

The observed increase of $V_{m}$ can be attributed to:

[1] The replacement of one $\mathrm{Cd}$ cation with ionic radius $\mathrm{R}_{\text {ion }}$ $=109(\mathrm{Pm})$ by two La cation with ionic radius $\mathrm{R}_{\text {ion }}=117 \mathrm{Pm}$, for each.

[2] It is supposed that, the oxgyen anions concentration in the glass networks may be gradually increased, since one oxygen anion of $\mathrm{CdO}$ was replaced by three oxygen anions of $\mathrm{La}_{2} \mathrm{O}_{3}$. This can be confirmed by calculating the number of oxygen ion density in the glass network, using the following equation:

$$
N_{O-i o n s}=\sum_{i} x\left[\left(d W t_{i} / M W_{i}\right) N_{n}\right]
$$

where $d$ is the density \& $W t$ is the weight percentage of each component, $M_{W}$ is the molecule weight of each; $N_{n}$ is Avogadro's number.

Fig. (7) confirm that the number of oxygen ion density increased gradually as lanthanum oxide was gradually increased. That is the oxygen network extended, and in turn act to increase the molar volume.

It is well known fact that some electric charges can be precipitated on the used shielding glass, hence the semiconduction properties of the prepared glasses was checked in order to be sure that, the formed charges can be drown to the earth through an earthing cable that connected to the used shield.

The total conductivity $\sigma(\mathrm{T}, \omega)$ has been measured as a function of temperature and frequency for the studied glass system, and the temperature dependence conductivity at different frequencies,

$$
\sigma(T, \omega)=\sigma_{d c}+\sigma_{a c}
$$

The sample that contain 4 mol $\% \mathrm{La}_{2} \mathrm{O}_{3}$, was depicted in Fig. 
(8) as a representative curve. It can be stated that all other samples showed approximately similar behavior.

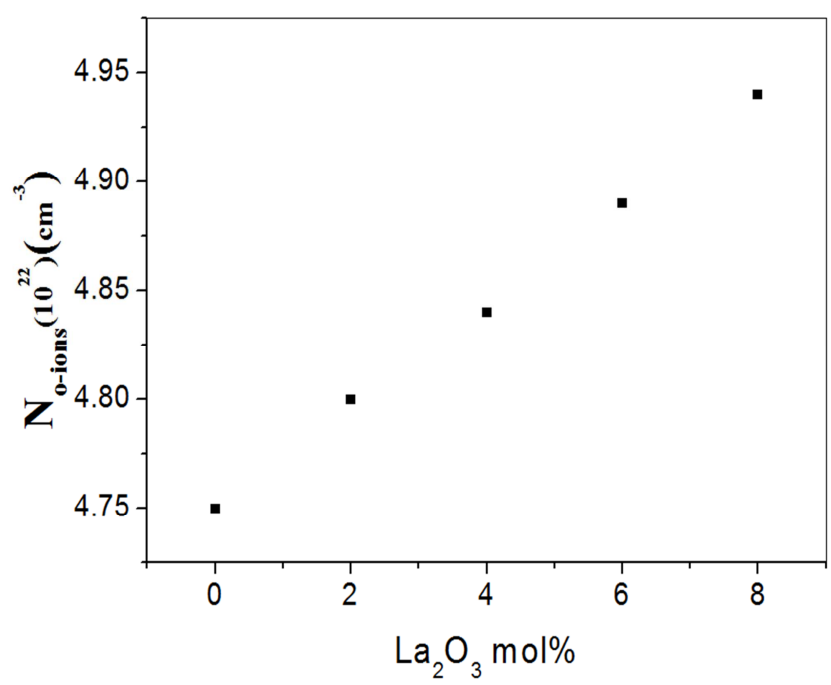

Fig. (7). The gradual change in the number of oxygen ion density versus $\mathrm{La}_{2} \mathrm{O}_{3}$ content.

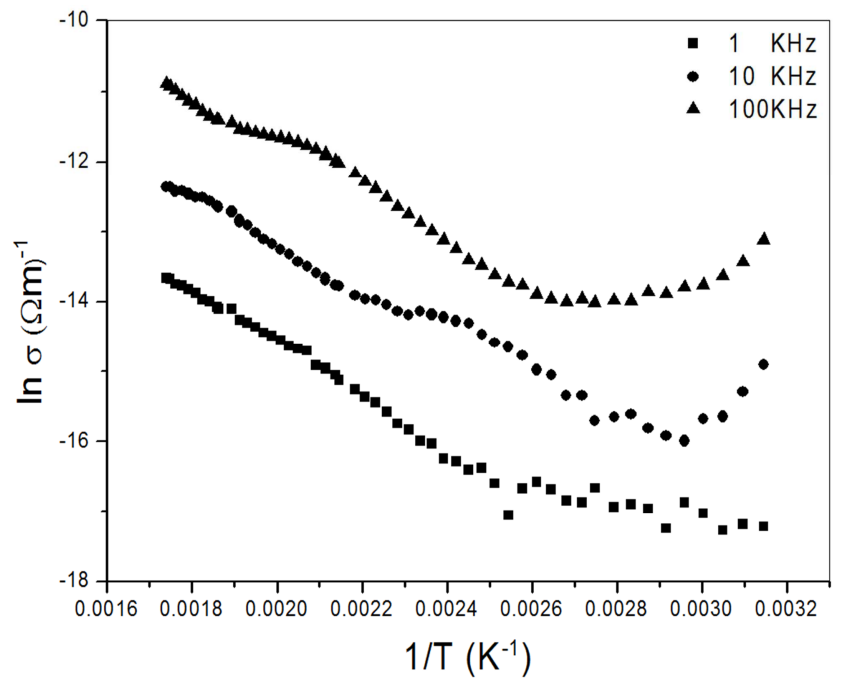

Fig. (8). Temperature and frequency dependence total conductivity for the sample containing 4 mol\% $\mathrm{La}_{2} \mathrm{O}_{3}$, as a representative curve.

From this figure, it is clear that the total conductivity increases with increase of both frequency and temperature. Also $\ln \sigma_{\mathrm{ac}}$ was found to increase linearly with the increase in temperature, which reveals the semiconducting behavior of the studied glass samples. That is the change in $\ln \sigma$ is entirely temperature and frequency dependent over the whole temperature range used.

The ac conductivity of all amorphous materials and glasses follows the universal power law,

$$
\sigma_{a c}(\omega)=" \omega^{s}
$$

where " is a constant (weakly temperature dependent), $S$ is the exponent factor (usually less than unity) and $\omega$ is the angular frequency.

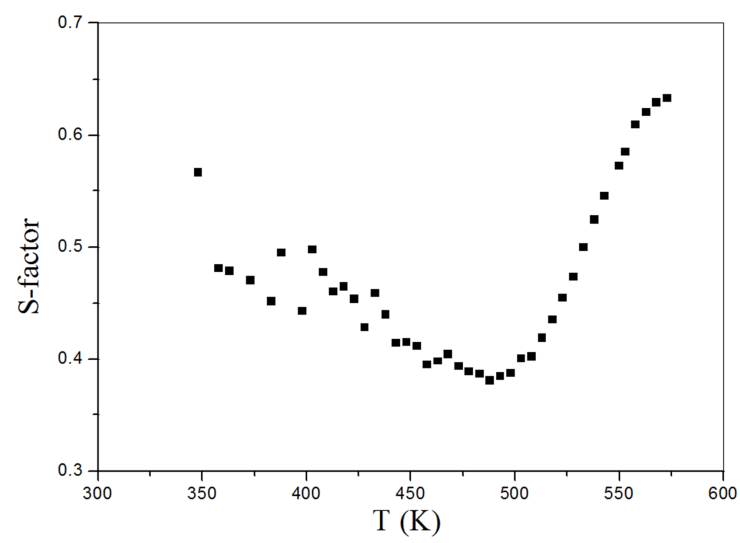

Fig. (9). The variation of the S-factor versus temperature for the sample containing $2 \mathrm{~mol} \% \mathrm{La}_{2} \mathrm{O}_{3}$, as a representative curve.

Fig. (9) represents the variation of the S-factor with temperature, for the sample contains $2 \mathrm{~mol} \% \mathrm{La}_{2} \mathrm{O}_{3}$, as representative figure. It appeared that, from $R T$ up to $475 \mathrm{~K}$, the $\mathrm{S}$-factor shows a gradual decrease, while from 475 up to $575 \mathrm{~K}$, the S-factor shows an increase. The $\mathrm{CBH}$ and $\mathrm{SPH}$ models are the dominant conduction mechanism in these two ranges of temperatures respectively [22]. This was expected because of the agreement between the experimental behavior of the exponent factor $S$ and those predicted by these models. All samples show approximately similar behavior.

Fig. (10) represents the obtained values of the total conductivity, for the studied glass system as a function of $\mathrm{La}_{2} \mathrm{O}_{3}$ content at 373 and $403 \mathrm{~K}$. It can be seen that it decreased by the increase of $\mathrm{La}_{2} \mathrm{O}_{3}$ content. The decrease of the conductivity may be due to:

[1] The increase of the molar volume leads to increase the distance between atoms, and this in turn increases the electron hopping distance. This decreases the electron hopping between cations, and finally decreases the conductivity.

[2] Also the replacement of cadmium by lanthanum cations acts also to decrease the conductivity where $C d$ has two oxidation states while $L a$ has only single oxidation state.

[3] $C d$ has activation energy $\left(E_{g}\right)=2.3 \mathrm{eV}$ while $L a$ has $\mathrm{E}_{\mathrm{g}}=4.2 \mathrm{eV}$.

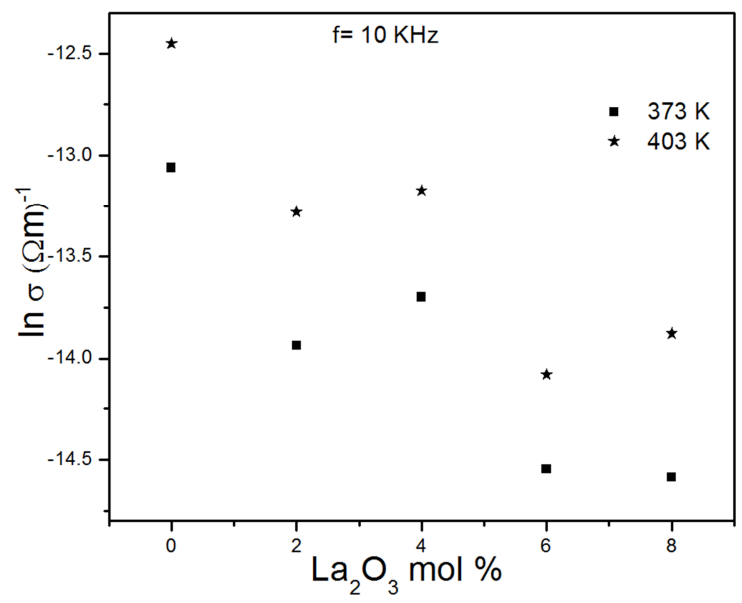

Fig. (10). The total conductivity as a function of $\mathrm{La}_{2} \mathrm{O}_{3}$ content for the studied glass system, at $373 \& 403 \mathrm{~K}$ and fixed frequency $(10 \mathrm{k} \mathrm{Hz})$. 
The dielectric constant $\left(\varepsilon^{\prime}\right)$ temperature dependence was studied for the investigated glass system in the temperature range from $R T$ to $575 \mathrm{~K}$, and at three different frequencies (1, $10,100 \mathrm{KHz}$.). The observed change in $\varepsilon^{\prime}$ was represented graphically in Fig. (11), (representative figure) as a function of both temperature and frequency. From this figure, it can be seen that $\varepsilon^{\prime}$ appeared approximately stable, as the temperature was gradually increased, then it starts to increase gradually with different rates corresponding to the different applied frequencies. Also, at any constant temperature the change in $\varepsilon^{\prime}$ was observed to be inversely proportional to the applied frequencies. This behavior may be due to the fact that as the frequency was gradually increased the orientation polarization decreased since it takes more time than the electronic and ionic polarization. It can be noticed that at low temperature, the dielectric constant appeared to be temperature and frequency independent, while at high temperature, it increased gradually as the temperature was increased. This behavior can be attributed to the orientation polarization which is related to the thermal motion (vibration) of the molecules and/or to the space charge polarization due to the bond defects in the glass network [23, 24]

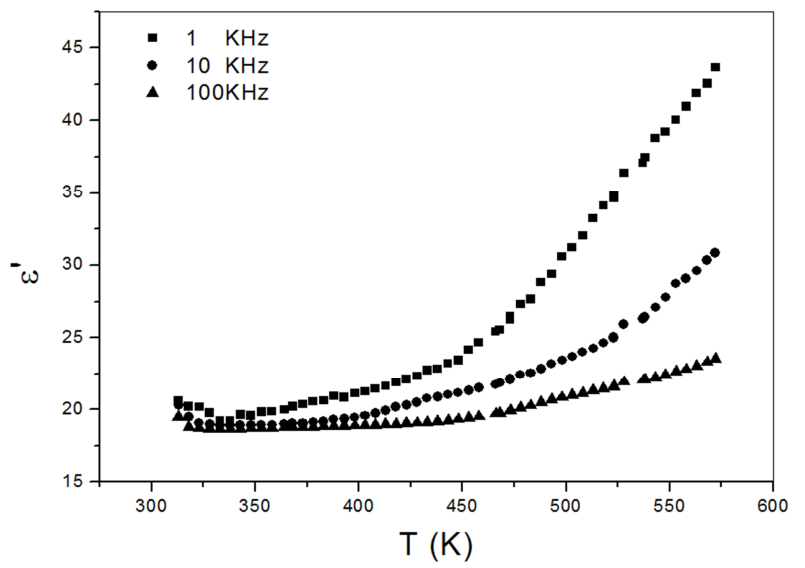

Fig. (11). Dielectric constant temperature and frequency dependence of sample containing $4 \mathrm{~mol} \% \mathrm{La}_{2} \mathrm{O}_{3}$, as a representative curve.

The dielectric loss $\left(\varepsilon^{\prime \prime}\right)$ factor as a function of temperature and frequency was also studied in the temperature range from $R T$ to $575 \mathrm{~K}$ and at three fixed frequencies 1,10 and $100 \mathrm{KHz}$. Fig. (12) exhibits $\varepsilon^{\prime \prime}$ as a function of temperature and frequency of sample No. 4 ( representative figure). Similar behavior was also obtained for all the studied samples. It can be noticed that at relatively low temperature $\varepsilon^{\prime \prime}$ appeared to be temperature and frequency independent, while at high temperature, it increases gradually as the temperature was increased such that the rate of increase is inversely proportional to the frequency. This behavior can be attributed to the relaxation phenomenon that can be divided into three parts, the conduction loss, the dipolar loss and the vibrational loss. Since the conduction loss is proportional to $\left(\sigma_{\omega}\right)$, therefore the conduction loss increased as the conductivity increased, (which is a function of temperature), similar behavior was obtained for the rest of the studied samples [23-25].

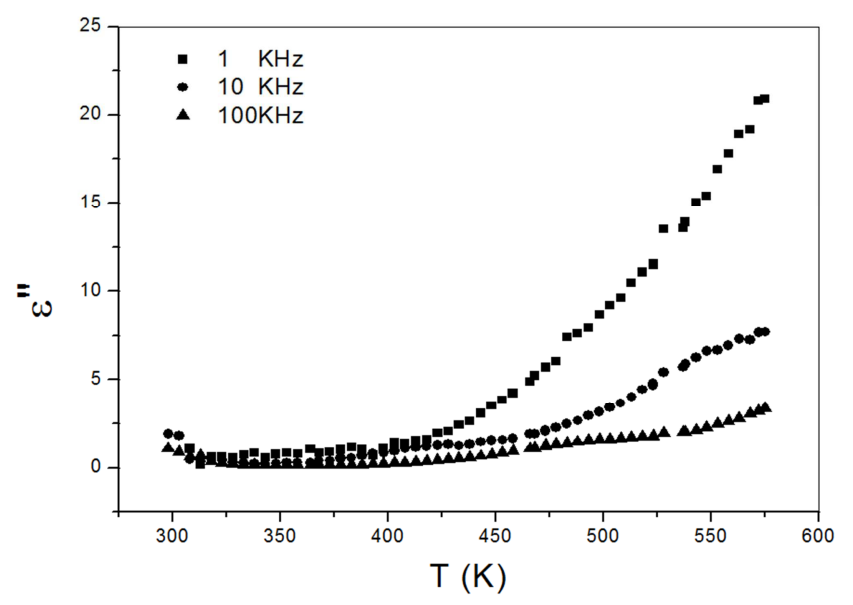

Fig. (12). The variation of the dielectric loss versus temperature at different frequencies of sample containing 4 mol\% $\mathrm{La}_{2} \mathrm{O}_{3}$, as a representative curve.

\section{Conclusion}

According to the obtained results within the aim of this work it can be concluded that gamma-ray shielding glass can be manufactured from phosphorus pent-oxide as host glass with $30 \%$ blast furnace slag and $20 \%$ some heavy metal oxides. In this study $\mathrm{CdO}$ and $\mathrm{La}_{2} \mathrm{O}_{3}$ have been used.

As $\mathrm{La}_{2} \mathrm{O}_{3}$ was increased at the expense of $\mathrm{CdO}$ the density as well as molar volume increased and hence the gamma-ray mass attenuation coefficient increased and consequently the HVL decreased. All the studied glasses showed semiconductor behavior and both the $\mathrm{CBH}$ and $\mathrm{SPH}$ models can be successfully used to describe the conduction mechanisms at low and high temperatures respectively. The conductivity showed a decrease with the gradual increase of $\mathrm{La}_{2} \mathrm{O}_{3}$ content. It was recommended that, it is preferable to use the studied glass as shielding materials for high gamma-ray energies than for low gamma-ray energies.

\section{References}

[1] H. Savastona, V. Agopyan, A. M. Nolasco and L. Pimentel, Construct. Build. Mater., 13 (1999) 433.

[2] Song Shou-Meng, LIU Su-jun and WU Hai-bin, J. Glass and Ceramics, (11) 5 (1983) 5 .

[3] M. Beijing, China Environment Annual Committee, China Environment Science Press, (1994).

[4] Liu Cheng-jun, Shi Pei-yang, Zhang Da-yong and Jiang Mao-fa, J. Iron and steel research International, (14) 2 (2007) 73.

[5] M. M. Hassan, Ph.D. Thesis, Azhar Univ., (2012).

[6] J. H. Campbell and T. I. Suratwala, J. Non-Cryst. Solids, 263 \& $264(2000) 318$.

[7] A. M. Abdel-Ghany, A. A. Bendary, T. Z. Abou-Elnasr, M. Y. Hassaan and A. G. Mostafa, Nat. Sci. 12 (2014) 146.

[8] C. Dayanand and M. Salagram, Ceram. Int., 30 (2004) 1731. 
[9] R. K. Brow, J. Non-Cryst. Solids, 263 (2000) 1.

[10] L. M. Sharaf El-Deen, M. S. Al Salhi and M. M. Elkholy, J. Non-Cryst. Solids, 354 (2008) 3762.

[11] O. Cozar, D. A. Magdas and I. Ardelean, J. Non-Cryst. Solids, $354(2008) 1032$.

[12] Y. He and D. E. Day, Glass Technol., 33 (1992) 214.

[13] S. Jiang, M. Myers and N. Peyghambarian, J. Non-Cryst. Solids, 239 (1998) 143.

[14] S. Dai, A. Sugiyama, L. Hu, Z. Liu, G. Huang and Z. Jiang, J. Non-Cryst. Solids, 311 (2002) 138.

[15] I. W. Donald, J. Mater. Sci., 28 (1993) 2841.

[16] D. E. C. Corbridge, "The Structural Chemistry of Phosphorous Compounds", Topics in Phosphorous Chemistry, 3 (1966) 71.

[17] S. T. Reis, D. L. A. Faria, J. R. Martinelli, W. M. Pontuschka, D.
E. Day and C. S. M. Partiti, J. Non-Cryst. Solids, 304 (2002) 188.

[18] F. Chen and D. E. Day, Ceram. Trans., 93 (1999) 213.

[19] S. H. Morgan, R. H. Mgruder and E. Silberman, J. Am. Ceram. Soc., (70) 12 (1987) 378.

[20] A. K. Wittenauer, M. Sc. Thesis, University of Missouri-Rolla, (2002).

[21] Q. Li, M. Sc. Thesis, University of North Dakota, (2002).

[22] R. Elliot, Adv. Phys.,18 (1987) 31.

[23] A.M. Abdel-Ghany, Ph.D. Thesis, Azhar Univ., (2011).

[24] L. Yunfei, Y. Zhang and Huang Weiwei, J. Non- Cryst. Solids, 112 (1989) 136.

[25] B. Rous, P. J. Miller and W. M. Risen, J. Non-Cryst. Solids, 28 (1978) 193. 